\title{
On the role of cultures of (out-)migration in the migration decisions of young people in shrinking regions of Central Germany
}

\author{
Frank Meyer ${ }^{1}$ and Tim Leibert ${ }^{2}$ \\ ${ }^{1}$ Department of Geography, TU Dresden, Dresden, 01069, Germany \\ ${ }^{2}$ Leibniz Institute for Regional Geography, Leipzig, 04328, Germany \\ Correspondence: Frank Meyer (frank.meyer1@tu-dresden.de)
}

Received: 11 January 2021 - Revised: 4 June 2021 - Accepted: 15 June 2021 - Published: 20 July 2021

\begin{abstract}
The patterns, motivations, and consequences of the outmigration of young adults from rural areas is a classic topic in population geography. In our paper, we first take a critical look at statistical analyses and cartographic representations of migration patterns of young adults in rural areas using Central Germany ${ }^{1}$ as an example, stressing the shortcomings of quantitative analyses of residential mobility. We argue that migration is a complex social process, taking place as the result of the interplay of demographic, socio-structural, political, economic, and production-related factors involving the mobile individuals, as well as other actors, discourses, and practices. Following this, we discuss the emergence of cultures of (out-)migration in rural areas characterised by heightened mobility over longer periods of time and possible approaches to analyse such regional phenomena. We hence aim at a deepening of the concept of "culture of migration" and an expansion of the debate on motives and practices of migration to include psychological approaches, as well as a complex systems perspective.
\end{abstract}

\section{Introduction}

Outmigration from rural peripheries is a classic topic in population geography. The patterns, motives, and consequences of leaving the countryside were described and analysed in numerous studies (e.g. Wiest, 2016; Meyer, 2017). It also receives a lot of attention in the - often emotionally charged - political, public, and media debate on internal migration. Numerous German and international studies have shown that migration in general, and especially migration from structurally weak rural areas, is age- and gender-selective, with young adults and women being more likely to leave (e.g. Kaberis and Koutsouris, 2013; Leibert, 2016; Makkai et al., 2017). Looking at the motives for migration, there is evidence of a dominance of educational and career-related aspects in the migratory considerations of young adults (e.g. Hansen and Aner, 2017). These aspects can be made compre-

\footnotetext{
1 "Central Germany" is frequently used as an umbrella term for the southern part of eastern Germany, i.e. the federal states of Saxony, Saxony-Anhalt, and Thuringia.
}

hensible in statistical and cartographic representations that are in high demand in political debates.

Maps and statistics do not, however, adequately reflect the complex realities of life; this is especially true for young adults, whose residential and migration biographies are often particularly unsteady as phases of living alone, sharing a flat, or living with a romantic partner alternate with one another or with a temporary return to the parental home (see, for example, Zorlu and Kooiman, 2019). These volatile and multi-local aspects are often not adequately reflected in population statistics whose assumptions and concepts are based on a stable primary residence. Phases of presence and absence are more complex and multi-layered than the statistical numbers suggest - and this is all the truer for research on feelings of belonging and connectedness.

Bearing in mind such complexities, a new strand of population and migration research has gained in importance: qualitative methods, discourse theory, and partly psychologically informed methodologies (e.g. Carling and Collins, 2018). From this micro-perspective, it becomes clear that the narrative of job-related or training-related outmigration is too 
reductionist and that the decision to migrate involves complex considerations, sometimes misinformed expectations and idealistic yet socially contested hopes of the young adults themselves and their social environment. In the context of the debate about cultures of (out-)migration, an attempt has been made to overcome these incongruences based on empirical work (e.g. Meyer, 2017). As part of this work, the complex interrelationship between discursive and practice-related aspects of migratory considerations and decisions were examined to be able to use subject-related factors to explain those cumulative developments that are ultimately depicted as depopulation, ageing, or rural outmigration in statisticalcartographic studies.

Our paper builds on the results of four research projects with adolescents and young adults conducted by the authors between 2010 and 2019 in different rural districts in the German Free States of Saxony and Thuringia, as well as in Saxony-Anhalt. The conceptual thoughts in this paper are based on quantitative surveys and group discussions with pupils in grades 9-12, as well as biographical interviews with women and men in their early 20s and expert interviews with relevant stakeholders, e.g. administration employees (see, for example, Leibert and Wiest, 2012, and Meyer, 2017, for more information on methods).

The aim of our paper is threefold: (1) based on a critical examination of statistical data analyses, we focus on (2) a deepening of the concept of "cultures of (out-)migration" as meso-phenomena at the intersection of discourse and practice and (3) an expansion of the debate on motives and practices of migration to include psychological approaches and a complex systems perspective. We begin this paper by giving a statistical overview of current migration patterns of the so-called "educational migrants", young people between the ages of 18 and 25, highlighting the shortcomings of the data and quantitative approaches using official statistics in general. We then give a short overview on the state of research dealing with the question of why young people leave their (rural) home regions, followed by conceptual considerations on the emergence of "cultures of (out-)migration". We perceive cultures of (out-)migration as open and complex systems. Section 5 deals with research perspectives and political measures regarding migration. Finally, we conclude the paper with thoughts on the implications of cultures of (out)migration for policy makers and local authorities.

\section{Outmigration of young adults from Central Germany ...}

\section{1 ... what do we know ...}

Since German reunification in 1990, the so-called new Länder (states) were strongly affected by the interconnected demographic processes of depopulation, selective migration, and ageing. The Free State of Saxony for instance has lost $15 \%$ of its original population between 1990 and 2018 .
In some municipalities, e.g. the cities of Hoyerswerda and Weißwasser in Upper Lusatia, a region especially affected by deindustrialisation in the eastern part of the state, the population has declined by more than $50 \%$ in just 30 years (Leibert, 2020a).

In the 30 years since reunification, eastern Germany has lost 1.2 million people to the western part of the country through internal migration. Young adults between the ages of 18 and 25 have been especially likely to "go west" (Stawarz et al., 2020) leaving behind an ageing population, especially in rural areas (Leibert, 2020a). In addition to this age selectivity, outmigration from rural areas of eastern Germany is also sex-selective with young women being more likely to leave, resulting in highly skewed sex ratios in many rural districts (Leibert, 2016). In recent years, a certain trend reversal has taken place. For the first time in decades, eastern Germany had positive (albeit small) net migration gains with Western Germany in 2017. The east-west migration of young adults, the outmigration of this age group from rural areas in eastern Germany, and the sex selectivity of these migration streams have also declined in recent years (Leibert, 2020b; Stawarz et al., 2020). However, given the severe demographic problems of rural eastern Germany - ageing, depopulation, and unbalanced sex ratios - it would be premature to celebrate these changes as a turning point in the demographic fate of this regions (Stawarz et al., 2020).

Figure 1 shows the migration balance of the so-called "educational migrants" in the states of Saxony, Saxony-Anhalt, and Thuringia by sex and size group of municipalities. Looking at the bars for women and men separately, the analysis produces a clear result: the smaller the municipality, the more negative the migration balance. Comparing the migration balances by sex shows that outmigration of young women is more pronounced than outmigration of coeval men in municipalities with less than 20000 inhabitants. According to the trend, young men are more likely to move to medium-sized towns, while young women flock to large cities. However, in the considered age group, the specialisation of universities significantly influences the migration patterns. Technical universities with a predominantly male student body (e.g. Dresden, Ilmenau) shift the overall migration balance toward a surplus of men. Cities that host universities with a stronger focus on social sciences or the humanities (e.g. Leipzig) are, on the other hand, especially attractive for young women.

\section{$2.2 \ldots$ and what do we not know?}

Based on the statistical data readily available in Germany, we know that rural areas are especially affected by the outmigration of young people between the ages of 18 and 25 and that there are pronounced urban-rural differences also within the countryside. What we do not know is who the migrants are and what their motivations and reasons for leaving are. These knowledge gaps are, on the one hand, linked to insufficient or 


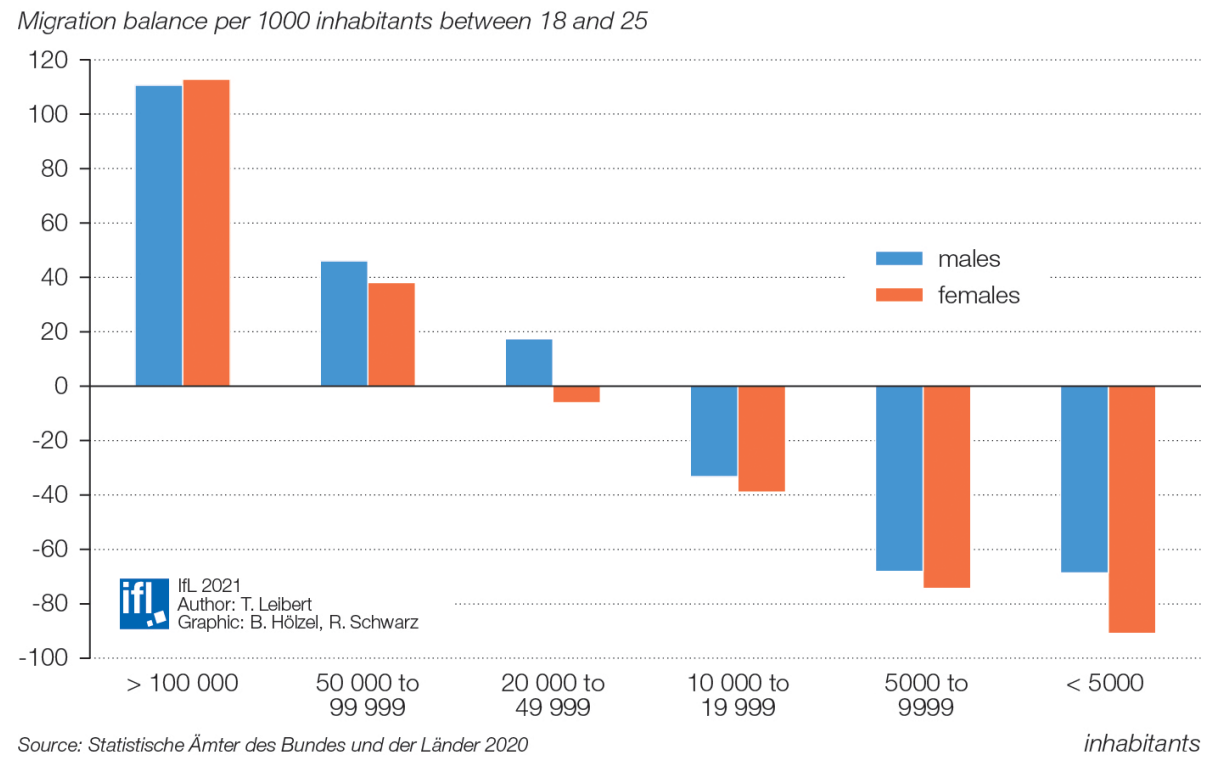

Figure 1. Central Germany: migration balance in the age group 18-25 by sex and population in 2017 from our own calculations. Data source: StÄBL 2020.

non-existent data and, on the other hand, to methodological and conceptual challenges.

What are the characteristics of movers and stayers? Do young people leave their rural home regions only temporarily to attend university or to complete vocational training or do they leave for good? Unfortunately, German statistics do not provide data to answer these questions. Statistical offices in Germany only collect data on the last relocation but not on an individual's migration biography. Additionally, many students retain their parental home as their main residence and only register a secondary residence at their place of study (even if this is their de facto centre of vital interest). Both the number of inhabitants and the number of migrants are calculated based on main residences. This means that official statistics underestimate the outmigration of young adults from rural areas. What is more, German migration statistics only include information on the sex, age, nationality, and marital status of the migrants but not on, for example, employment status or educational attainment. The concept of "educational migrants" is also problematic. Between the ages of 18 and 25, young people in Germany may start and finish their vocational training or university studies. They may undertake different (types of) moves, e.g. leaving (or later returning to) the parental home, going to university, moving in with a partner, or first-employment-related moves. The patterns and motivations of student migration and employmentled migration of university graduates follow different logics and expectations (Smith and Sage, 2014). Labelling the diverse migration patterns of an age group with an interpretative name can result in oversimplifying the complexity of young adult migration and overemphasising a certainly im- portant migration motive at the expense of others, e.g. leaving the parental home.

On a critical note towards quantitative research on mobility and migration in general, Greene and Rau (2018) find fault with the tendency of many studies to treat context as a set of external variables, which leads - from their point of view - to ignoring "the role of individuals as active and socially connected change agents whose practices both shape and reflect the structure, compositions and logics of the settings they inhabit" (Greene and Rau 2018:63). Scientific discourses are not neutral, nor are maps and figures. They convey political interests and the social constructedness of objects of research (see Wintzer, 2014). This is, of course, also true for Fig. 1 and the arguments presented above. Research on certain topics and places can hence contribute to or reinforce stigmatisation of the places in question and their inhabitants. The report by Kröhnert and Klingholz (2007) which generated considerable media interest in the late 2000s has contributed to the marginalisation and stigmatisation of rural eastern Germany in general and young rural men in particular (see also Wiest, 2016, and Rolfes and Mohring, 2009, for narratives and discourses of stigmatisation of the rural east). In the title of their publication, the authors use the soccer analogy of a club being sent down to a lower league (Abstieg) to describe rural eastern Germany as Abstiegsregionen and characterise the young men living there as disadvantaged, insinuating that they are not academically inclined and are right-wing voters and unattractive mates for the clever girls who consequently turn their back on rural eastern Germany and those left behind. The effects of stigmatising discourses on and within rural regions, especially in eastern Germany, has been touched on in the literature (e.g. Meyer et al., 2016, 
or Wiest, 2016). The question of if and how territorial stigmatisation contributes to the emergence and consolidation of cultures of (out-)migration nevertheless warrants further scientific attention (see also Sect. 3).

\section{Why do young people leave their (rural) home regions?}

The body of literature regarding migratory decision-making of young adults has grown enough to provide us with knowledge about the basic mechanisms of migration regarding contemporary international, national, and regional flows. Coulter et al. (2016:353) propose a life-course perspective to analyse internal migration and short-distance residential mobility to better capture the fluidity, diversity, and de-standardisation of contemporary lives. They argue that three perspectives are especially relevant in this respect: (1) the concept of linked lives, (2) enabling, directing, and constraining influences of structural forces, and (3) the influence that broader societal, economic, and political processes exert on individual lives.

The concept of linked lives implies that "lives are lived interdependently, and socio-historical influences are expressed through this network of shared relationships" (Elder et al., 2003:13). This perspective attracts attention to the relationality of migration: linking the lives of different people, linking movers and non-movers, linking migrants and institutions, economic stakeholders, and so on (Findlay et al., 2015:391). In terms of linked lives, the complex exchanges of support between young adults and their parents also affect the patterns of leaving and returning to the parental home (e.g. Zorlu and Kooiman, 2019). The same is true for rural marriage markets (Kaberis and Koutsouris, 2013) or the formation of romantic relationships in general, especially at times when a considerable number of young people search for partners. Social pressures from relatives, friends, and within everyday institutions such as schools should also be mentioned here as they have proven to be most influential in shaping adolescent orientations towards (im-)mobility (Meyer, 2017).

Halfacree and Merriman (2015) make another important point: migration is a process with no obvious endpoint, which implies that migration decision-making also has a temporal dimension and that the decision to leave can be seen as a practice that is nested in an individual's life-course biography and unfolds over time (see Coulter et al., 2016). The production of biographies and subjectivities is hence connected to and intertwined with space, place, and history (Farrugia and Wood, 2017; Stockdale and Catney, 2014). Outmigration of young adults from rural eastern Germany is a good example. The legacy of the German Democratic Republic and the social and economic distortions of the 1990s and early 2000s have continued to shape the age- and sex-selective migration behaviour of young East Germans at least until the beginning of the last decade (Leibert, 2016). In the East German context, regional disparities of available vocational, ed- ucational, and other career-related options were specifically highlighted as influences impacting on individual migration decision-making (see Meyer, 2017). Furthermore, a different availability of leisure activities such as malls or cinemas may not impact a migratory decision directly, yet it influences adolescent experiences regarding their home region in contrast to what other regions may provide and thus has a flanking influence on later migratory reasoning. Migratory decisions are, thus, to a certain extent influenced by political decisions on where certain educational or vocational institutions are established. More generally, labour and social policies, e.g. regarding a further flexibilisation of the labour market and unemployed benefits, have so far contributed to an increased acceptance of career-related mobility. However, one should also consider that not all people have the same opportunities to fulfil their desires to move (or to stay) (Findlay et al., 2015). These opportunities can be economic in nature, linked to social policies or the embeddedness in social relations.

However, this is not the full picture. Opportunities are not objective but linked to an individual's beliefs, attitudes, goals, and emotions, as well as their relations with their peers. Social identities, feelings of belonging, mobilities, the perceptions of what constitutes a "good" life, and also individual responses to mobility imperatives and attitudes towards living in urban or rural areas are intersectional experiences and may be influenced by class, race/ethnicity, gender, and sexuality (Terman, 2020; see also Farrugia et al., 2014). Terman (2020:22) claims that "intersectional methods and analysis of identity, place, mobility, and belonging help us better understand the limiting issues and potential liberating solutions for young people in search of place and belonging in rural communities". We can conclude that the decisions to move or stay put are influenced by both the local context (e.g. economy, infrastructure, migration history) and by classed and gendered competencies, considerations, and expectations at the individual level (Farrugia et al., 2014; Stockdale and Catney, 2014).

Other influences which we consider to be rather underilluminated in research on young adult migration patterns include the considerable influence of communicative patterns - e.g. the dream of fleeing rural boredom - which can be drivers of adolescent outmigration (e.g. Meyer et al., 2016; Meyer, 2017). In this context, social media, and technological tools such as WhatsApp or Skype, may help one to keep contact and thus may ease the feeling of disconnectedness after outmigrating (Meyer, 2017). Furthermore, societal trends of individualisation, "metronormativity", i.e. the "material and symbolic hegemony of urbanization and globalization in relation to rural people and places" (Terman, 2020:22), and regional negative images (see, for example, Wiest, 2016) strengthen adolescent tendencies to consider leaving their home region. 


\section{The emergence of cultures of (out-)migration}

In the transition from youth to adulthood, migration (both domestic and international) is often a "normative, taken-forgranted social practice" (Smith and Sage, 2014:112). If this social practice becomes a taken-for-granted rite of passage for young people in a region, the term "culture of (out)migration" (see, for example, Hahn and Klute, 2007, for the African context) seems justified to label circumstances where outmigration is socially negotiated as an inevitable step in one's life or as "a crucial and necessary social act, that is quasi-compulsory for certain social categories" (Horváth, 2008:774). ${ }^{2}$

In his paper on cultures of migration from rural Romania, Horváth (2008) highlights three different uses of the term, connected to (1) the factual existence of such a lived pattern of behaviour, (2) the norms and ideas organising the migration discussion, and (3) the possibility that migration may have acquired some symbolic functions. Horváth (2008) finds that these approaches share a claim to identify structures that are common in decision-making processes of young adults. However, the term does not necessarily involve people actually moving "but rather the ideas that people share about these movements" (Easthope and Gabriel, 2008:173). The label "culture" is, hereby, not meant to essentialise the concept of culture as a regionalised set of personal traits but rather a semantic to highlight a dominant role that migration plays in regional discourses. Besides, it is important to take into account that "young people" are not a homogeneous group and that, as a consequence, different cultures of (out)migration (and cultures of staying, for that matter) related to different classed and gendered narratives, experiences, and life plans may coexist at the same place and time.

The presence of cultures of (out-)migration in rural areas is a critical phenomenon for regions suffering from economic decline. While the term itself may draw criticism for its metaphorical nature and essentialist undertone, several scholars have empirically observed the implications of a culture of (out-)migration (see, for example, Easthope and Gabriel, 2008, or Wiest, 2016). Besides such accounts that use the label of "culture", the discursive dimension of migration can also be covered under various terms. Carling (2002:17) uses the concept of "emigration environment" to refer to "discourses about emigration, place and poverty" and the "social, economic and political context which is largely common to all members of the community". He stresses that actual migration may be a "demographic event", yet "people who consider it as an option relate to migration through the meanings with which it is embedded" (Carling 2002:13). As noted above, the subjective evaluation of migration-related opportunities is important enough in the process of decisionmaking to require qualitative inquiry. This is especially true

\footnotetext{
${ }^{2}$ In the following, we will concentrate on the aspect of outmigration as the prevalent trajectory in our research.
}

against the backdrop that with quantitative methods, it is virtually impossible to capture how gender identity, sexual orientation, ethnic or religious background, disabilities, or social class interact with life plans and influence the decisions to move or stay put.

From the perspective of post-structuralist discourse theory, we can conceptualise cultures of (out-)migration as regional discourses (performed in the region) and/or regionalised discourses (involving articulations about the region). However theoretical such an understanding may appear, it has the advantage of rejecting linguistic restrictions and encompassing social phenomena that may be of significance for the subjects involved. The regionalised discourses can be interpreted as dynamic sets consisting of semantics, actions, objects, etc. that ascribe meanings to regions using specific signifiers and have a certain relevance for the subjects' process of reasoning (also Meyer and Miggelbrink, 2013). Hence, regional and regionalised discourses are systems of articulation in and/or about a region that organise knowledge in and/or about the region in specific ways and are of relevance for those subjects involved.

We consider cultures of (out-)migration as sedimented patterns of discursive - communicative and bodily - practices related to migration: this means that in regions where such a culture is prevalent, adolescents grow up knowing that outmigration is a taken-for-granted aspect of their biography; they either witness a large number of acts of outmigration and/or are subjected to frequent discussions about their personal prospective migration decision. The main determinants for the emergence of a culture of (out-)migration are a high ratio of out-commuting or outmigrating adults over a long time leading to many examples of outmigration that can be witnessed by the adolescents and that set the normative standard for mobility practices, whereas regional opportunities are prone to be disregarded (Meyer, 2017). Instead, social expectations become common in the way that those unwilling to leave sense the need to justify staying (Meyer, 2017). A negative internal image about the region's capability to satisfy the needs of its younger population may intensify this development further.

In sum, it is the critical mass of exemplary experiences of outmigration within many social circles in regions with a culture of (out-)migration which leads to the establishment of a widely shared social standard of outmigration. On the one hand, this standard is a matter of practice due to a large number of people commuting or leaving. On the other hand, it is a matter of communication because a possible outmigration is an everyday topic in the family, in the circle of friends, or in school for many adolescents in rural regions. Both aspects of discourse stabilise each other and, thus, create the benchmark for many social interactions within such a region. 


\section{Research perspectives on migration beyond the individual's reasoning}

\subsection{Why is there a need of novel research perspectives?}

The reason for the long-lasting endeavour to explain and theorise migration lies, according to Han (2000), in its complex social nature, taking place as the conclusion of the interplay of demographic, socio-structural, political, economic, and production-related factors. According to Han (2000:22), this seems to be the reason why there is a lack of universally valid and scalar-sensitive explanations for migration; prevalent migration theory, according to Meyer and Miggelbrink (2014), often remains focused on rather describing the mere mechanics of migration than dissecting the subjective processes of reasoning. However, there have been some scholars calling for attempts to bridge the gap between the subjective component of migration and its socio-structural and societal contexts (e.g. de Haas, 2010; Beetz, 2009; Speck et al., 2009). Following Meyer and Miggelbrink (2014), this could involve integrating research on the negotiation of migration in social networks, acknowledging non-linear and non-rational decision-making, taking cumulative effects through past migration dynamics and role models into account, and highlighting the discursive importance of migration in regional milieus. ${ }^{3}$ In the following section, we will present two approaches that may help in understanding such cultures of (out-)migration from a research perspective and add further analytical layers to this concept.

\subsection{Subjectivity and migration in contemporary migration theory}

Our remarks on cultures of (out-)migration should have made clear that influencing migratory reasoning is not an easy task as the locus of making a migration-related decision is not just the individual person, but social networks inflict considerable influence on individual decisions. Furthermore, the context of the decision is also not just political frameworks as they may frame individual horizons of possibilities and

\footnotetext{
${ }^{3}$ However, we will not tackle issues related to politics of belonging that have been brought up recently in the context of the reflexive turn in migration research (e.g. Nieswand and Drotbohm, 2014; Dahinden et al., 2021). Whilst this strand of research clearly has the potential to reflect on categories of analysis and contexts of problematisation in migration research (Dahinden et al., 2021:327), its focus on international migration as a matter of public, scholarly, and political problematisation is not at the core of our empirical research that drives this study. Rather than asking about discursive processes that problematise migrating subjects or conclude political acts of bordering (see Amelina, 2020), we are interested in the subjects' own reflections on what has played a role in their decision-making process. This is, ultimately, in line with the call of Nieswand and Drotbohm (2014:2) to shed light on the internal perspective (Binnenperspektive) of migrants and is more concerned with a refined engagement in explaining acts of migration.
}

constraints (such as the distribution of vocational opportunities), yet they often do not follow certain societal trends and interests. Such trends, however, also do not solely determine migratory decision-making as - the research is clear on that - there is a rational component in migratory reasoning often related to opportunistic career choices, and, of course, individual dispositions, e.g. of biographical (or often undeterminable) nature, form the stencil that influences which aspects, interests, or constraints may be prioritised by the individual.

From the conceptual point of view of post-structuralist social theory and psychoanalytical theory, the subject can be seen as a manifestation of multiple attempts and offers of structuration (further elaborated in Meyer and Miggelbrink, 2013), eventually taking up a subject position as discursive identity (see Davies and Harré, 1990). Consequently, subjects are exposed to the discourse as they are the entities (re-)producing it (see Butler, 1997). Such an approach considers humans as subjects in the sense that they are unstable social entities that continuously navigate a multitude of discursive influences (see Meyer and Miggelbrink, 2013). Focusing on just one of the sites of migratory decision-making means reducing the complexity of this social phenomenon to a level where the resulting mechanism is not representing the actual reality and may therefore fail to offer insights into why and how certain migratory acts happen. Considering the intersectional postulate, analytically dissecting the specific processes and influences that migrating individuals are subjected to and taking part in may reveal the complex ways that the societal realm has a part in making outmigration a viable option of individual subjects. Thus, new ways of interrogating not only the age-selective but also gender-selective migratory patterns in German internal migration could emerge.

In recent years, a number of scholars have attempted to illuminate such complex subjects, e.g. under the label of post-rational migration theory, with scholars being devoted to those psychological processes that shape individual decision making with all its volatility, complexity, irrationality, and emotionality. This dimension of migratory decisionmaking (see Mai and King, 2009) stems from the fact that the migrants' relationship to their home place is often "emotionally charged, representing ambivalent feelings" (Wiborg, 2004:427) - often related to biographical experiences and social relations. Outmigration, complementarily, also has been shown to be loaded with emotional associations (e.g. Meyer, 2017; Wiest, 2016) or even "ethical implications" related to poverty (Carling, 2002:17). Whether or not, and to what extent, such layers of meaning permeate the subject's decision must be reconstructed for individual cases. It may not be impossible to aggregate such cases into groups based on commonalities, yet as helpful as such attempts are in a pursuit of a (for the sake of a better word) "bigger picture", they are as destructive in disguising the specific biographical, emotional, representational, and non-representational details that form 
the basis for an individual's ultimate decision for or against a migratory act.

In pursuing this approach of social inquiry that ultimately bridges the gap between an individualistic and societal account of migration, some scholars utilise psychoanalytical conceptualisations of the human subconscious to dissect the basic aspects of human emotionality such as aspirations and desire (e.g. Carling and Collins, 2018) and relate them to normative social orders. For instance, Collins (2014) contributes an understanding of the role of desire within the process of generating a subject's wish to migrate related to higher education within South-east Asia. Detailing the case of Singapore, Collins et al. (2014) specifically dissect the political practice of promoting academic excellence to generate students' mobility aspirations for transnationally enlisting in universities. Methodologically, some scholars have analysed drawings of their respondents (e.g. Findlay et al., 2013; Shubin et al., 2014), often relying on Jacques Lacan's teachings in psychoanalysis yet also attempting to apply methods other than interviews and focus groups (on questions of method, see Bondi, 2014). Whereas the psychoanalytical approach may have been a particularly influential one so far, other approaches that tackle a subject's social embeddedness may supplement this strand of research.

Pursuing such a line of thought leads to the following:

I. Cultures of (out-)migration can thus be considered not only an empirically grounded socio-geographical metaphor for those regions where certain powerful discursive patterns related to normalised outmigration have developed.

II. Instead, cultures of (out-)migration can be considered more specifically those discursive phenomena characterised by a regionalised powerful discourse about outmigration that permeates individual decision making in such a way that it serves the emergence of individual desires to leave.

III. Consequently, cultures of (out-)migration may also be considered a research perspective that highlights the importance of investigating regional and regionalised collective socio-discursive phenomena and their role in shaping specific individual decisions to migrate.

Such an approach may help in understanding (just to name a few) the embeddedness of subjects (and their decisions) in social networks and milieus, the relevance of regionalised images and discursive patterns for individual decisions, the rifts individuals experience when their wishes and social expectations clash, or the temporal discontinuities related to growing up and the dynamics of becoming an adolescent for migratory decision making. Consequently, such perspectives can enrich works on quantified and mapped migration trends and provide insights into what Carling and Collins (2018) call "drivers of migration". However, it is not the only perspective that transcends scalar or paradigmatic boundaries.
In the following, we want to offer a complementary research perspective for how to tackle regionalised cultures of (out)migration.

\subsection{Cultures of (out-)migration through the lens of complex systems theory}

Adolescent migration from rural areas has a paradoxical dimension: many studies have shed light on the career-based drivers for outmigration, which triggered local and regional initiatives to diversify regional labour markets, attract new employers, and promote programmes that may incite early interest in regional employment opportunities in the rural youth (see Meyer, 2017). However, on the other hand, such measures were often not met with much interest in adolescents who, from the perspective of administrative employees, seemed to ignore such efforts and remained locked in their outwardly oriented disposition (see Meyer, 2017). In order to analyse the reason why, for example, regional programmes to initiate early contacts between interested adolescents and regional employers often fail to create sustainable effects, we want to discuss cultures of (out-)migration from the perspective of complex systems.

Following O'Sullivan's (2004) summary of complexity research's implications for human geography, the concept of aggregatory complexity may refer to the characteristics of systems which are composed of several distinct components that interact with each other (O'Sullivan, 2004:284). Considering this line of thought, research on one or many of these components (e.g. migratory considerations, regional policy, national labour policies) would have to focus on the relations between these components, posing challenges yet also potential for geographic research:
Aggregate complexity is of particular interest to geographers because it implies that the local spa- tial configuration of interactions affects outcomes at the whole system level. How local interactions "scale up"; to effects at larger scales is a familiar concern to geographers. (O'Sullivan, 2004:284)

Yet, what components can be sketched in our example of adolescent migration? From a micro perspective, biographical experiences, personal aspirations, and choices, as well as subjective dispositions, are, of course, at the core of our interest. Nevertheless, these individual manifestations are situated within local, regional, and larger social networks (e.g. family, friends, schools, clubs) and are influenced by (individual and collective perceptions of the) regional histories, opportunities, and images. On a larger scale, rural cultures of (out-)migration take place against the backdrop of sociodemographic polarisation between rural and urban regions, partially influenced by policies related to, for example, educational and vocational policies and to labour and social welfare policies (e.g. regarding their priority of pressuring individuals to move for job opportunities, financial aid to stu- 
dents). More generally, European regional policies and funding mechanisms contribute to regional opportunities, whilst societal processes of regional and regionalised stigmatisation (e.g. Meyer and Miggelbrink, 2013) have contributed to a volatile image of the rural as being unfit for young adults. All these institutions, norms, rules, circumstances, societal dynamics, and individual acts are part of an interconnected web of influences that impacts on individual migratory decisions - often triggering the use of the attribute "complex" whilst trying to describe the scalar, regional, and individual differentiation of these factors and their interdependence.

From a conceptual point of view, three key characteristics of complex systems are of importance here:

- Complex systems consist of a number of distinct elements (e.g. human beings, machines). These are interdependent in the way that each element property and role within that system is related to other elements in a non-determining way (see Bar Yam, 1997).

- Complex systems are dynamic in that they self-organise into emergent phenomena (O'Sullivan, 2004). Referring to Phillips (1999), O'Sullivan (2004) goes on to question whether geographic approaches may then consider simultaneous processes of convergence and divergence (O'Sullivan, 2004:285): While convergence can appear as aggregated individual and local phenomena (e.g. adolescent outmigration as a local and societal phenomenon), divergence can be considered to revolve around regional differentiation in such processes.

- Complex systems are path dependent. Path dependence, famously tackled in geography, e.g. in the polarisation approach of Myrdal (1957) or, among many, the work of Grabher (1993) on regional lock-in processes, revolves around the notion "that a system's trajectory is a function of past states, not just the current state" (O'Sullivan, 2004:285) and that positive feedback loops may likely happen and reinforce certain trends.

There are several authors that have introduced a complexity perspective on migration. For instance, Castelli (2018) dissected various drivers that influence individual decisions to migrate with regard to certain economic, environmental, political, social, and demographic circumstances, individual characteristics, and obstacles, which all feed into a specific decision (Castelli 2018:3). Terminologically, he nevertheless remains rather metaphoric in the use of "complex". For Leloup (1996), in contrast, migration is "an integrated process in its socio-economic and spatial environment", with the individual level being related to behaviour that is tightly connected to macroscopic variables (e.g. employment) (Leloup 1996:103). The dynamics of migration themselves, from Leloup's view, are partly predictable (in that they are often related to economic or demographic dynamics) and partly unpredictable due to uncertainty and "indirect or cumulative effects" (Leloup 1996:104). He goes on to elaborate a causal model of migration processes in Senegal. Lastly, Baláž et al. (2016) highlight the complexity of the individual decisionmaking process itself and have contributed a refined understanding of how subjects navigate information in terms of selecting and weighing based on experimental methodological approaches.

What all these approaches have in common is the notion that large-scale migration flows may not only be seen as mere aggregations of individual acts but as complex systems of social actions: in these systems, actions (e.g. migratory acts) are complex as they cannot be considered to happen distinctly from each other. Instead, acts of migration may, for instance, serve as examples for other acts and, in sum, lead to the emergence of a social pattern which itself then has productive potential as it shapes political considerations, social interactions, and individual decisions.

Continuing our list of possible conceptualisations of cultures of (out-)migration from Sect. 5.2, we further consider them to be the following:

IV. They are migration-related epistemological transects that allow for an investigation into the complex nature of migratory decision making. Thus, they serve as exemplary complex systems in that they consist of a multitude of elements across multiple scales (ministries, regional actors, aspiring migrants, family, etc.) whose actions are interdependent. The perspective of cultures of (out-)migration as transects highlights that not all the interactions of these elements are focused on each other but that we as researchers cut out the portion of their interactions that we consider relevant. Cultures of (out)migration are path dependent as they usually are identified in regions that have had a long history of outmigration and commuting, sometimes induced by an initial loss of employers due to economically critical phases, that has led to a normalisation of migration, and cultures of (out-)migration are dynamic as regionally polarised demographic patterns emerge from them whilst contributing to an overall age- and sex-selective phenomenon of rural outmigration.

Based on these conceptual considerations, research perspectives may revolve around, firstly, understanding the components of these systems, their interactions, and the regional and biographical pathways leading up to a current situation, as well as possible scenarios for future development. Secondly, these considerations allow for insights into the reasons why regional policy makers are not able to exert considerable influence on adolescent outmigration: they are just a part of a more complex system of elements, on just one scale of action, and have, thus, limited influence on the totality of interactions that ultimately leads up to outmigration. Whilst, yes, personal choices determine whether a migration takes place, it remains unclear to what extent exactly each of 
the numerous institutions, laws, policies, relations, etc. determine whether that choice is made.

\section{Conclusion and outlook}

Based on recent socio-demographic dynamics in eastern Germany and our past research experience on migratory decision-making processes of rural adolescents in this region, we highlighted the need to consider research frameworks that enable us to look beyond just the individual act or general circumstances. Instead, we concluded the relevance of discursive and practice-related regional milieus called cultures of (out-)migration and highlighted the need to integrate research perspectives on subjective processes of reasoning, as well as socio-structural and societal contexts, in the endeavour to explain large-scale migration processes.

Yet as promising as such attempts may be, our considerations are as instructive for an applied view on migration. First of all, if migration is an individual and collective act at the crossroads of subjective aspirations, societal expectations, and opportunistic necessities, then it cannot be considered bad or undesired (as is frequently criticised in the context of the reflexive turn in migration theory) for it is just the outcome of specific yet complex dynamics leading up to it. Second, if the factors for migration do originate from various societal scales and sites yet intersect in a region for a culture of (out-)migration to emerge, then any political attempt from within than region to tackle outmigration is limited in its effect as it does not manage to tackle all of the factors involved. Third, while some of these factors may be influential for a number of regions (e.g. labour or social policies), regional path dependencies leading up to specific discursive milieus highlight the need to differentiate between the migratory dynamics of different regions and between small and mid-tier cities, as well as to consider their different contexts.

While we would conclude that research on migration needs to further engage with what complexity means in the practice of migration, policy makers as well must factor it into their measures: acknowledging and tackling several influences simultaneously, implementing and coordinating measures on different scales and in different policy sectors, and monitoring the effects.

Data availability. The manuscript is based on empirical data that have been partially covered elsewhere (e.g. Meyer at al., 2016; Leibert and Wiest, 2012; Leibert, 2020a, b).

Author contributions. Both authors have contributed equally to the creation of this manuscript.

Competing interests. The authors declare that they have no conflict of interest.
Disclaimer. Publisher's note: Copernicus Publications remains neutral with regard to jurisdictional claims in published maps and institutional affiliations.

Acknowledgements. The authors would like to thank the two anonymous reviewers for their highly constructive and helpful comments.

Review statement. This paper was edited by Nadine Marquardt and reviewed by two anonymous referees.

\section{References}

Amelina, A.: After the reflexive turn in migration studies: Towards the doing migration approach, Popul. Space Place, 27, e2368, https://doi.org/10.1002/psp.2368, 2021.

Baláž, V., Williams, A. M., and Fifekova, E.: Migration Decision Making as Complex Choice: Eliciting Decision Weights Under Conditions of Imperfect and Complex Information Through Experimental Methods, Popul. Space Place, 22, 36-53, https://doi.org/10.1002/psp.1858, 2016.

Bar-Yam, Y.: Dynamics of Complex Systems, Addison-Wesley, Reading, Mas, 837 pp., ISBN 0-201-55748-7, 1997.

Beetz, S.: Analysen zum Entscheidungsprozess Jugendlicher zwischen 'Gehen und Bleiben', in: Regionale Abwanderung Jugendlicher. Theoretische Analysen, empirische Befunde, politische Gegenstrategien, edited by: Schubarth, W. and Speck, K., Weinheim, München, 135-151, 2009.

Bondi, L.: A Liminal Practice? Making Interdisciplinary Spaces for Psychoanalysis, in: Making Spaces. Putting Psychoanalytic Thinking to Work, edited by: Cullen, K., Bondi, L., Fewell, J., Francis, E., and Ludlam, M., Routledge, London, 37-54, ISBN 9781780491653, 2014.

Butler, J.: The Psychic Life of Power: Theories in Subjection, Standford University Press, Stanford, CA, 218 pp., ISBN 08047-2812-7, 1997.

Carling, J.: Migration in the Age of Involuntary Immobility: Theoretical Reflections and Cape Verdean Experiences, J. Ethn. Migr. Stud., 28, 5-42, https://doi.org/10.1080/13691830120103912, 2002.

Carling, J. and Collins, F.: Aspiration, Desire and Drivers of Migration, J. Ethn. Migr. Stud., 44, 909-926, https://doi.org/10.1080/1369183X.2017.1384134, 2018.

Castelli, F.: Drivers of migration: why do people move? J. Travel Med., 25, 1-7, https://doi.org/10.1093/jtm/tay040, 2018.

Collins, F.: Teaching English in South Korea: Mobility Norms and Higher Education Outcomes in Youth Migration, Child. Geogr., 12, 40-55, https://doi.org/10.1080/14733285.2013.851064, 2014.

Collins, F., Sidhu, R., Lewis, N., and Yeoh, B.: Mobility and Desire: International Students and Asian Regionalism in Aspirational Singapore, Discourse-Abingdon, 35, 661-676, https://doi.org/10.1080/01596306.2014.921996, 2014.

Coulter, R., van Ham, M., and Findlay, A.: Rethinking residential mobility: Linking lives through 
time and space, Prog. Hum. Geog., 40, 352-374, https://doi.org/10.1177/0309132515575417, 2016.

Dahinden, J., Fischer, C., and Menet, J.: Knowledge Production, Reflexivity, and the Use of Categories in Migration Studies: Tackling Challenges in the Field, Ethnic Racial Stud., 44, 535554, 2021.

Davies, B. and Harré, R.: Positioning: The Discursive Production of Selves, J. Theor. Soc. Behav., 20, 43-63, 1990.

De Haas, H.: Migration and Development: A Theoretical Perspective, Int. Migr. Rev., 44, 227-264, https://doi.org/10.1111/j.17477379.2009.00804.x, 2010.

Elder, G. H., Johnson, M. K., and Crosnoe, R.: The Emergence and Development of Life Course Theory, in: Handbook of the Life Course, edited by: Mortimer, J. T. and Shanahan, M. J., Springer, New York, 3-19, ISBN 978-0-306-47498-9, 2003.

Easthope, H. and Gabriel, M.: Turbulent Lives: Exploring the Cultural Meaning of Regional Youth Migration. Geogr. Res., 46, 172-182, https://doi.org/10.1111/j.1745-5871.2008.00508.x, 2008.

Farrugia, D. and Wood, B. E.: Youth and Spatiality: Towards Interdisciplinarity in Youth Studies, Young, 25, 209-218, https://doi.org/10.1177/1103308817712036, 2017.

Farrugia, D., Smyth, J., and Harrison, T.: Emplacing young people in an Australian rural community: an extraverted sense of place in times of change, J. Youth Stud., 17, 1152-1167, https://doi.org/10.1080/13676261.2014.901495, 2014.

Findlay, A., McCollum, D., Shubin, S., Apsite, E., and Krisjane, Z.: The Role of Recruitment Agencies in Imagining and Producing the 'Good' Migrant, Soc. Cult. Geogr., 14, 145-167, https://doi.org/10.1080/14649365.2012.737008, 2013.

Findlay, A., McCollum, D., Coulter, R., and Gayle, V.: New Mobilities Across the Life Course: a Framework for Analysing Demographically Linked Drivers of Migration, Popul. Space Place, 21, 390-402, https://doi.org/10.1002/psp.1956, 2015.

Grabher, G.: The weakness of strong ties; the lock-in of regional development in the Ruhr area, in: The Embedded Firm: On the Socioeconomics of Industrial Networks, edited by: Grabher, G., London, 255-277, 1993.

Greene, M. and Rau, H.: Moving across the life course: A biographic approach to researching dynamics of everyday mobility practices, J. Consum. Cult., 18, 60-82, https://doi.org/10.1177/1469540516634417, 2018.

Hahn, H. P. and Klute, G. (Eds.): Cultures of Migration, African Perspectives, Lit, Berlin, 291 pp., ISBN 978-3-8258-0668-2, 2007.

Halfacree, K. and Merriman, P.: Performing Internal Migration, in: Internal migration: geographical perspectives and processes, edited by: Smith, D., Finney, N., Halfacree, K., and Walford, N., Taylor \& Francis, Farnham, 149-164, 2015.

Han, P.: Soziologie der Migration. Erklärungsmodelle, Fakten, politische Konsequenzen, Perspektiven, Lucius \& Lucius, Stuttgart, 374 pp., ISBN 3-8282-0306-X, 2000.

Hansen, H. K. and Aner, L. G.: On the location dynamics of highly educated people migrating to peripheral regions of Denmark, Popul. Space Place, 23, e2076, https://doi.org/10.1002/psp.2076, 2017.

Horváth, I.: The Culture of Migration of Rural Romanian Youth, J. Ethn. Migr. Stud, 34, 771-786, https://doi.org/10.1080/13691830802106036, 2008.
Kaberis, N. and Koutsouris, A.: Under Pressure: Young Farmers In Marriage Markets - A Greek Case Study, Sociol. Ruralis, 53, 74-94, https://doi.org/10.1111/soru.12001, 2013.

Kröhnert, S. and Klingholz, R.: Not am Mann: von Helden der Arbeit zur neuen Unterschicht? Lebenslagen junger Erwachsener in wirtschaftlichen Abstiegsregionen der neuen Bundesländer, Berlin-Institut für Bevölkerung und Entwicklung, Berlin, 85 pp., ISBN 978-3-00-02-1678-7, 2007.

Leibert, T.: She leaves, he stays? Sex-selective migration in rural East Germany, J. Rural Stud., 43, 267-279, https://doi.org/10.1016/j.jrurstud.2015.06.004, 2016.

Leibert, T.: Demografische Strukturen und Entwicklungen in den ländlichen Räumen Sachsens: Nur Abwanderung und Schrumpfung?, Sächsische Heimatblätter, 66, 16-27, 2020a.

Leibert, T.: Wanderungen und Regionalentwicklung. Ostdeutschland vor der Trendwende? in: Regionalentwicklung in Ostdeutschland, edited by: Becker, S. and Naumann, M., Springer Spektrum, Berlin, Heidelberg, 199-210, ISBN 978-3-66260901-9, 2020b.

Leibert, T. and Wiest, K.: SEMIGRA - case study report: SachsenAnhalt: Targeted analysis 2013/2/15 final report - annex 2A, Leipzig, Esch-sur-Alzette, European Union, 107 pp., 2012.

Leloup, F.: Migration, a complex phenomenon, Int. J. Anthropol., 11, 101-115, 1996.

Mai, N. and King, R.: Love, Sexuality and Migration: Mapping the Issue(s), Mobilities-UK, 4, 295-307, https://doi.org/10.1080/17450100903195318, 2009.

Makkai, B., Máté, É., Pirisi, G., and Trócsányi, A.: Where have all the youngsters gone? The background and consequences of young adults' outmigration from Hungarian small towns, Europ. Countrys., 9, 789-809, https://doi.org/10.1515/euco-2017-0044, 2017.

Meyer, F.: Navigating aspirations and expectations: adolescents' considerations of outmigration from rural eastern Germany, J. Ethn. Migr. Stud., 44, 1032-1049, https://doi.org/10.1080/1369183X.2017.1384163, 2017.

Meyer, F. and Miggelbrink, J.: The Subject and the Periphery: About Discourses, Loopings and Ascriptions, in: Peripheralization: The Making of Spatial Dependencies and Social Injustice, edited by: Fischer-Tahir, A. and Naumann, M., SpringerVS, Wiesbaden, 207-223, ISBN 978-3-531-19018-1, 2013.

Meyer, F. and Miggelbrink, J.: Subjektivität und Kausalität in der Migration(sforschung) - Annäherungen an Rationalisierungen von Migrationsentscheidungen Jugendlicher in schrumpfenden Regionen, Raumforschung und Raumordnung, 73, 17-30, 2014.

Meyer, F., Miggelbrink, J., and Schwarzenberg, T.: Reflecting on the Margins: Socio-spatial Stigmatisation among Adolescents in a Peripheralised Region, Comp. Popul. Stud., 41, 285-320, 2016.

Myrdal, G.: Economic Theory and Underdeveloped Regions, Gerald Duckworth, London, 168 pp., 1957.

Nieswand, B. and Drotbohm, H. (Eds.): Kultur, Gesellschaft, Migration: Die reflexive Wende in der Migrationsforschung, SpringerVS, Wiesbaden, 346 pp., ISBN 978-3-658-03626-3, 2014.

O'Sullivan, D.: Complexity Science and Human Geography, T. I. Brit. Geogr., 29, 282-295, https://doi.org/10.1111/j.00202754.2004.00321.x, 2004. 
Phillips, J. D.: Divergence, convergence, and selforganization in landscapes, Ann. Assoc. Am. Geogr., 89, 466-488, https://doi.org/10.1111/0004-5608.00158, 1999.

Rolfes, M. and Mohring, K.: Diskursanalysen zur Abwanderung ostdeutscher Jugendlicher, in: Regionale Abwanderung Jugendlicher. Theoretische Analysen, empirische Befunde und politische Gegenstrategien, edited by: Schubarth, W. and Speck, K., Juventa, Weinheim, München, 69-90, ISBN 978-3-77991750-2, 2009.

Shubin, S., Findlay, A., and McCollum, D.: Imaginaries of the Ideal Migrant Worker: A Lacanian Interpretation, Environ. Plann., 32, 466-483, https://doi.org/10.1068/d22212, 2014.

Smith, D. P. and Sage, J.: The regional migration of young adults in England and Wales (2002-2008): a 'conveyor-belt' of population redistribution?, Child. Geogr., 12, 102-117, https://doi.org/10.1080/14733285.2013.850850, 2014.

Speck, K. and Schubarth, W.: Regionale Abwanderung Jugendlicher als Teil des demographischen Wandels - eine ostdeutsche oder gesamtdeutsche Herausforderung?, in: Regionale Abwanderung Jugendlicher. Theoretische Analysen, empirische Befunde und politische Gegenstrategien, edited by: Schubarth, W. and Speck, K., Weinheim, München, 153-171, 2009.

Statistische Ämter des Bundes und der Länder (StÄBL): Regionaldatenbank Deutschland, available at: https://www. regionalstatistik.de/genesis/online, last access: 29 October 2020.
Stawarz, N., Sander, N., Sulak, H., and Rosenbaum-Feldbrügge, M.: The turnaround in internal migration between East and West Germany over the period 1991 to 2018, Demogr. Res., 43, 993-1008, https://doi.org/10.4054/DemRes.2020.43.33, 2020.

Stockdale, A. and Catney, G.: A Life Course Perspective on UrbanRural Migration: the Importance of the Local Context, Popul. Space Place, 20, 83-98, https://doi.org/10.1002/psp.1758, 2014.

Terman, A. R.: Social identities, place, mobility, and belonging: Intersectional experiences of college-educated youth, J. Rural Stud., 77, 21-32, https://doi.org/10.1016/j.jrurstud.2020.04.033, 2020.

Wiborg, A.: Place, Nature and Migration: Students' Attachment to Their Rural Home Places, Sociol. Ruralis, 44, 416-432, https://doi.org/10.1111/j.1467-9523.2004.00284.x, 2004.

Wiest, K.: Migration and everyday discourses: Peripheralisation in rural Saxony-Anhalt from a gender perspective, J. Rural Stud., 43, 280-290, https://doi.org/10.1016/j.jrurstud.2015.03.003, 2016.

Wintzer, J.: Geographien erzählen: wissenschaftliche Narrationen von Geschlecht und Raum, Franz Steiner Verlag, Stuttgart, 309 pp., ISBN 978-3-515-10832-4, 2014.

Zorlu, A. and Kooiman, N.: Spatial trajectories in early life: Moving on or returning home?, Popul. Space Place, 25, e2268, https://doi.org/10.1002/psp.2268, 2019. 